\title{
Effect of Soil Organic Carbon Distribution on Riparian Nitrate Attenuation During Stream
} Stage Fluctuations

\author{
Nicholas Hammond, Chuanhui Gu, and Sarah Evans
}

APPALACHIAN
GEOLOGICAL AND ENVIRONMENTAL

Department of Geological and Environmental Sciences, Appalachian State University, Boone, NC, USA SCIENCES

\section{Introduction}

Riparian zones occur at the interface between surface water and groundwater. These zones are critical locations for the occurrence of biogeochemical processes such as denitrification. Denitrification is an important natural process that removes nitrate pollution in streams and groundwater resulting from anthropogenic inputs. Stream stage fluctuations leading to increased bank storage have a strong effect on the removal of river-borne nitrate through facultative anaerobic microbial denitrification, referred to as "hot moments." Since the availability of oxygen and organic carbon are considered to exert the greatest control on denitrification rates, denitrification can be significant when on denitrification during hot moments have focused on hydrologic controls as well as stream dissolved organic carbon input, but not the contribution of
organic-carbon rich riparian soils.

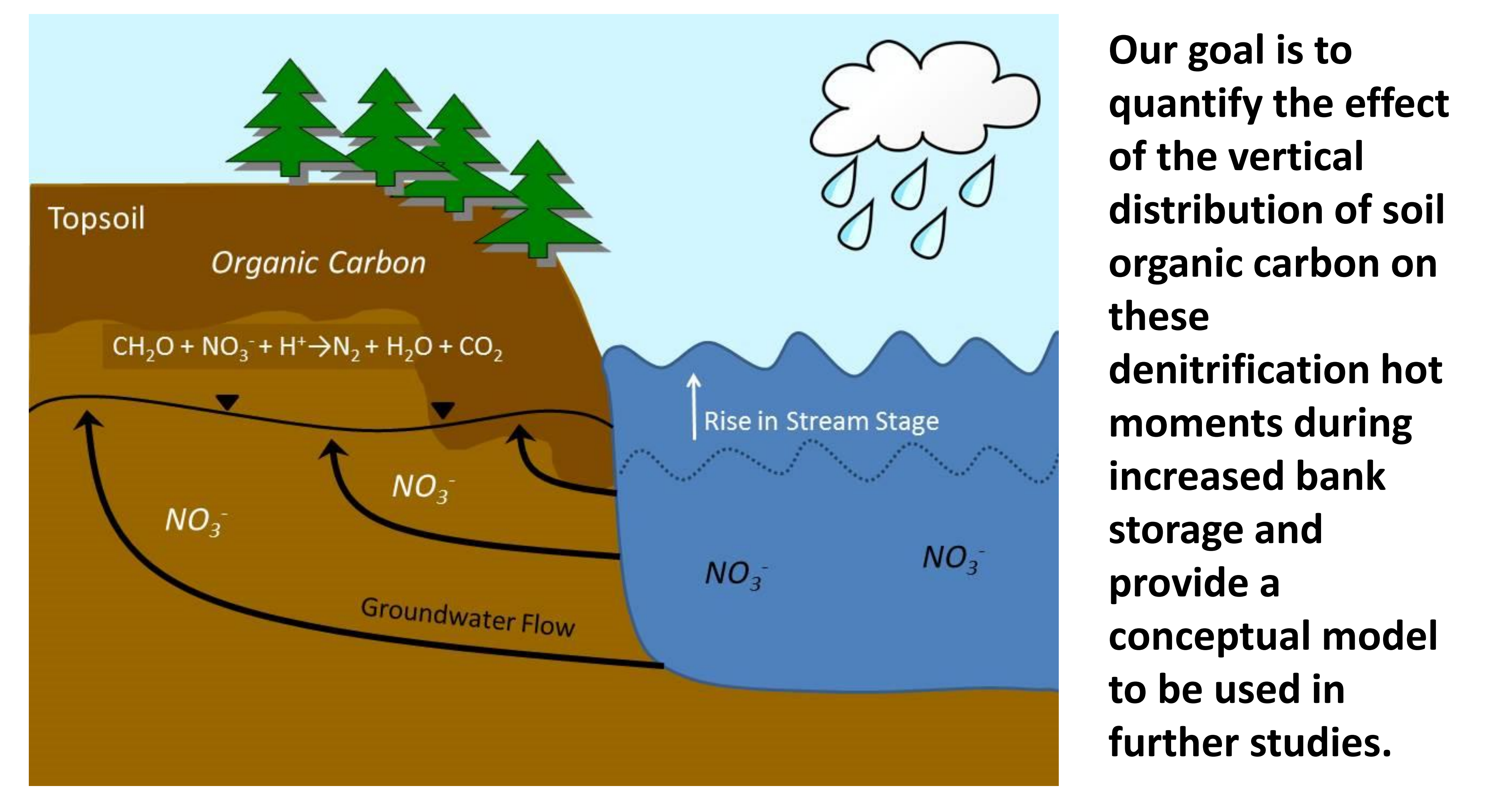

Figure 1. Schematic diagram of bank storage induced by stream stage rise and its effect on denitref

\section{Study Site}

The field data used in this
study was collected from
Boone Creek in Boone,
NC, USA (Figure 2). Boone
Creek is a third order
perennial stream in the
Upper South Fork of the
New River watershed,
located in the Blue Ridge
Province of Western NC.
The area of the Boone
Creek sub-basin is $5.3 \mathrm{~km}^{2}$
(Gu et al., 2015).
Annual average rainfall is 19000-1400 $\mathrm{mm} / \mathrm{rr}$. Normal mean annual air
temperature is $9.4^{\circ} \mathrm{C}$, ranging from a daily average temperature of $20.3^{\circ} \mathrm{C}$ in July
to -0.4 $4^{\circ} \mathrm{C}$ in January (Gu et al., 2015). The surrounding area is mountainous, with
an average slope of $27 \%$ (Gu et al., 2012 ). Boone Creek flows through an
urbanized area, including the Town of Boone and the Appalachian State
University campus, with a high degree of impervious surfaces nearby. The
percentage of impervious area within a $12.2 \mathrm{~m}$ buffer of all streams in the
drainage area is $32.2 \%$ (Gu et al., 2015).

\section{Modeling Methodology}

Model Domain \& Boundary Conditions

A 3-D finite difference model, MODFLOW-NWT, was used to simulate groundwater flow. The model domain was $50 \mathrm{~m}$ wide, $5 \mathrm{~m}$ tall, and $2.5 \mathrm{~m}$ across (Figure 3). The grid consisted of 1 row, 78 columns, and 25 layers divided into 1,950 cells. The subsurface was approxinated as homogenous and isotropic.

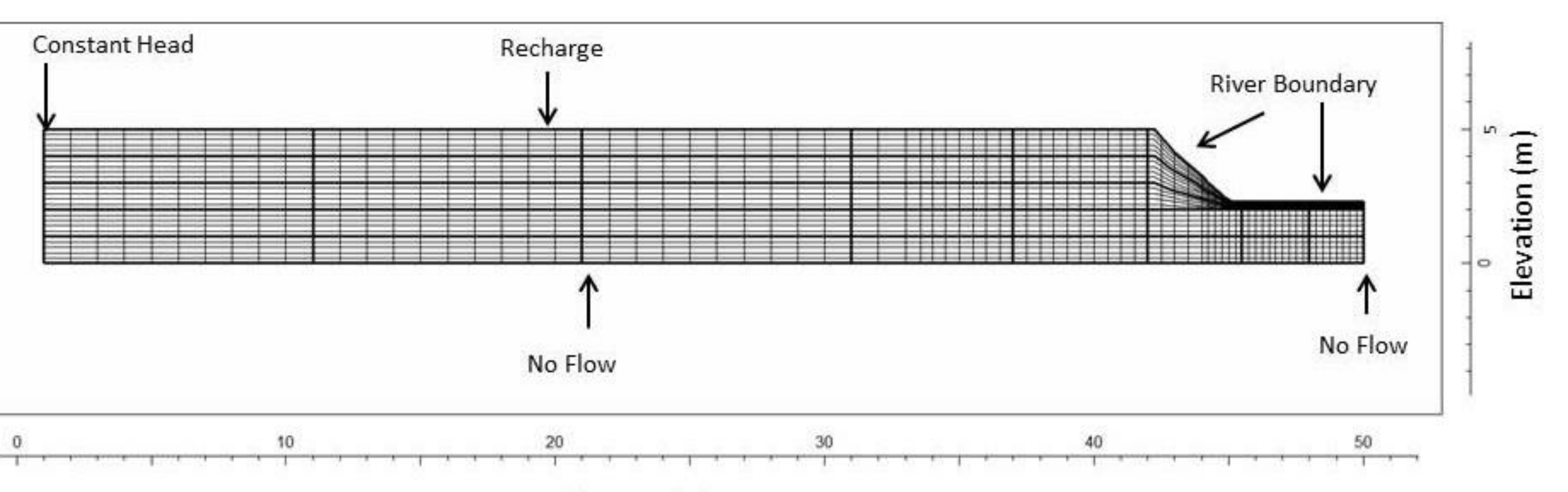

Distance $(m)$

Figure 3. MODFLOW-NWT model domain and boundary conditions. Table 1. Hydrologic parameters used in

Model boundary conditions are shown in Figure 3 . The (upslope) boundary was assigned a constant head of $3.5 \mathrm{~m}$. The top of the model was assigned a constant recharge rate of $0.864 \mathrm{~mm} / \mathrm{d}$ for the duration of the simulation. The bottom of the model and the right vertical boundary below the stream channel were assigned no flow bounday conditions. At the river boundary, the MODFLOW RI package, a head-dependent flux (or "leaky") boundary condition, was used to simulate surface water-groundwater interaction (Reilly, 2001)

\section{Hydrograph}

We chose a 36-hour period between 2:15

am on October 8, 2017 and 2:15 pm on October 9, 2017 that included a stream stage rise from approximately $0.18 \mathrm{~m}$ (baseflow) to a peak stage of $2.33 \mathrm{~m}$ (Figure 4). Nine stress periods were utilized with smaller time steps during the hour prior and the hour following peak stream stage.

Solute Transport Table 2. Chemical/physical parameters
used in MT3D-USGS simulation.

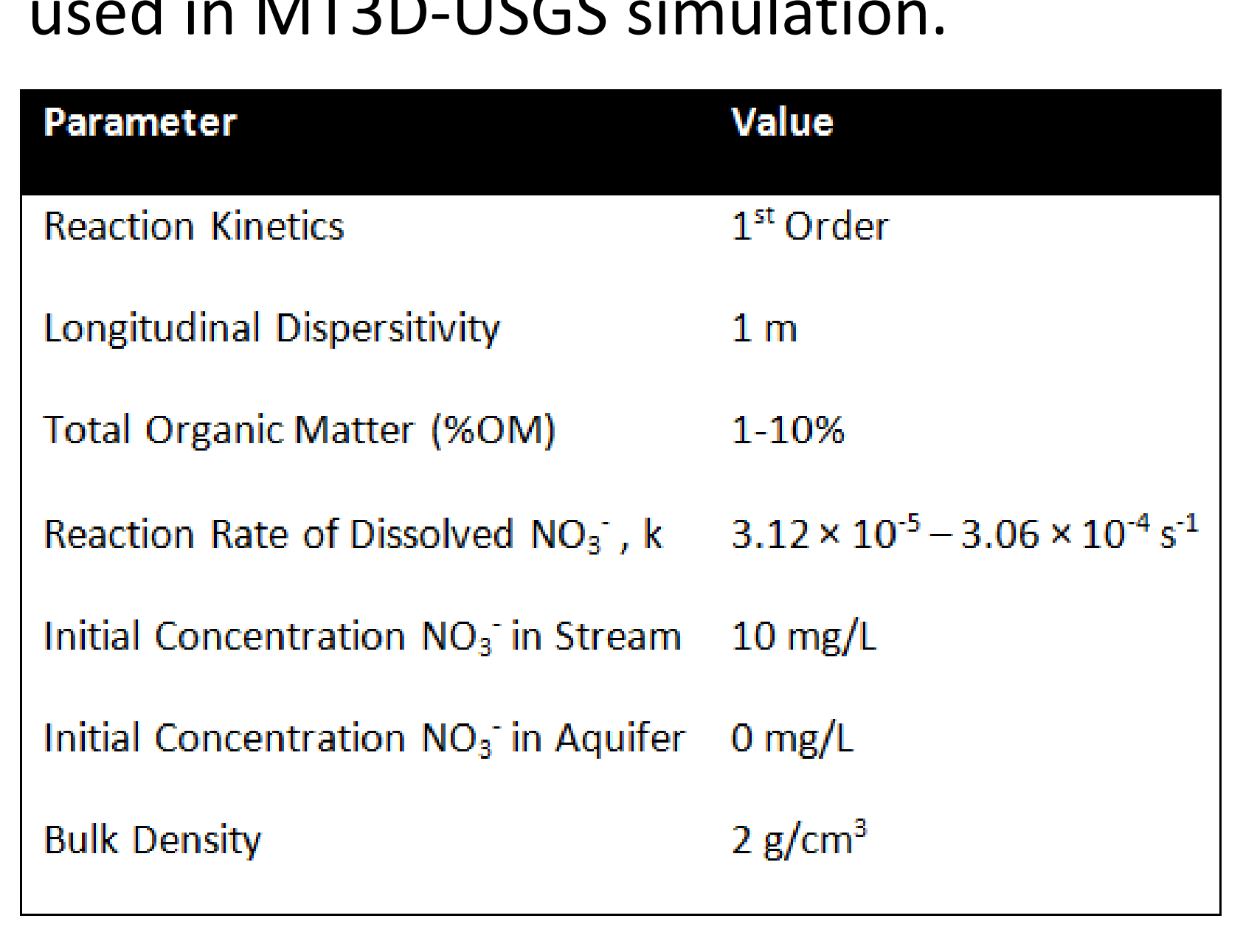

Chemical Reaction

$k=0.011 x+0.0025$

Where $\mathrm{k}$ is the denitrification rate and $X$ is total soil C ( $\mathrm{mg} / \mathrm{g})$.

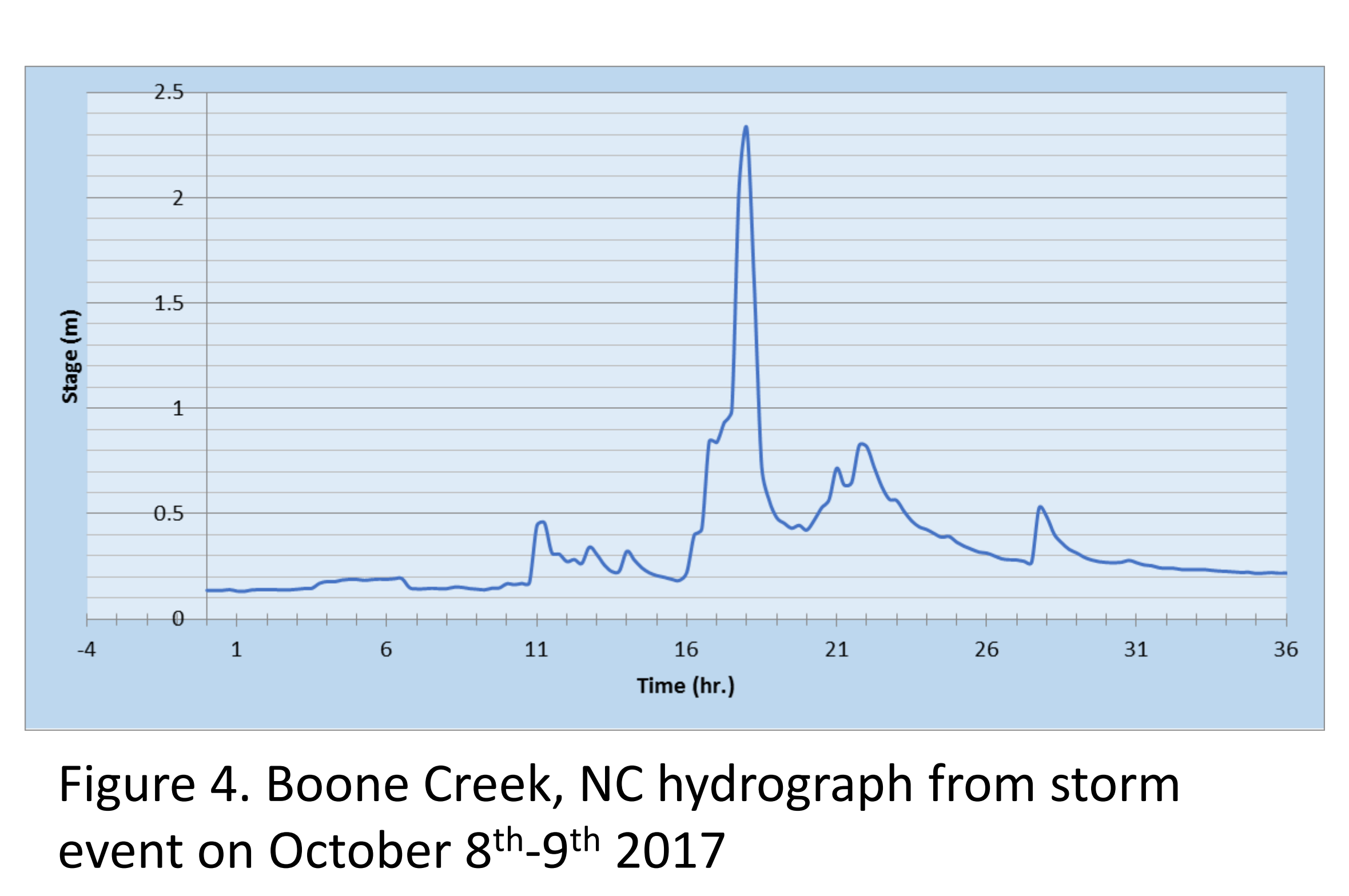

Figure 4. Boone Creek, NC hydrograph from storm
event on October $8^{\text {th-gth }} 2017$

Solute transport and the first-order decay reaction were modeled using the groundwater solute transport simulator MT3D-USGS. A sink-source mixing package was used at the river boundary to allow for solute to enter and exit the groundwater system, depending on the direction of flow. For the first simulation, a constant profile of $3 \%$ organic matter (OM) was assigned to a depth of $2 \mathrm{~m}$ and $<1 \% \mathrm{OM}$ below $2 \mathrm{~m}$. For the second simulation, the $\mathrm{OM}$ content ranged from $10 \%$ at the surface to $1 \%$ at $5 \mathrm{~m}$ depth. The total $\mathrm{OM}$ content was the same for each simulation.

The contribution of carbon (C) from OM-rich topsoils is kinetic-controlled. In this study, we simplified the nitrote over time could be described by fist-order kine The relationship between total soil carbon (\%OM) and the nitrate decay constant $k$, was derived using this regression equation defined by Stanford et al. (1975).

\section{Results}

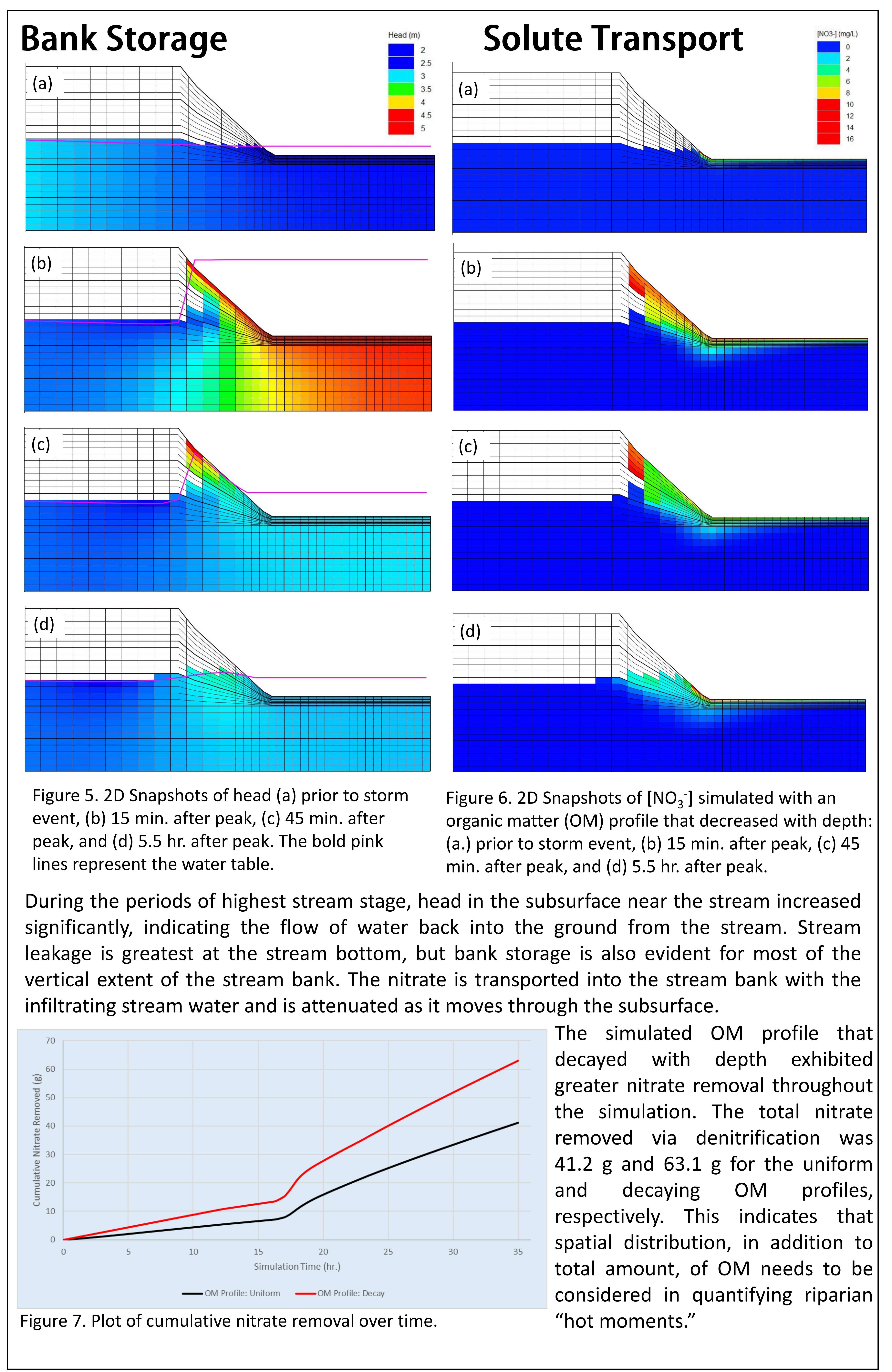

References

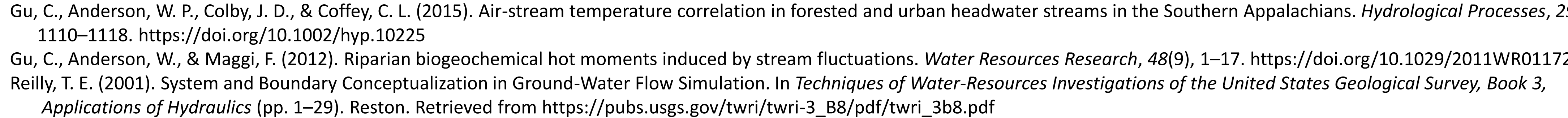

Acknowledgements 